\title{
DATA MANAGEMENT: \\ MANAGING DATA AS AN ORGANISATIONAL RESOURCE
}

SG Maritz (London)

Managing data as a resource is an important function of information management. Accurate and relevant data is the source of valuable information. By managing data efficiently, sound management decisions can be made. The traditional file environment is not appropriate for managing data; database management systems are the most popular choice for managing data effectively. Some of the broader trends in data management include outsourcing, data reuse, data re-engineering, archiving, data warehousing and data mining.

Keywords: data management, outsourcing, data reuse

\section{INTRODUCTION}

Managing data as a resource is an important managerial task in any organisation today. It is evident that business success depends not only on the possession of resources, but on the efficient utilisation of resources - data and information within an organisation and its environment form part of the strategic, tactical and operational resources of an enterprise (Lessing \& Scheepers 2001:3).

This article discusses data management as an aspect in the broader field of information management, as well as information as a resource and the concept of the 'new economy'. The importance of database management systems as opposed to traditional file systems is emphasised and some of the latest trends and developments in the field of data management are presented.

\section{THE IMPORTANCE OF DATA MANAGEMENT}

What is data management and how does it relate to the broader field of information management? Firstly, it is appropriate to distinguish between the terms of data and information. Rob \& Coronel (2000:4) explain the contrast between these two terms. Data are raw facts; the word "raw" is used to indicate that the facts have not yet been processed to reveal their meaning.

Information is processed data on which to base decisions. Managers spend 80 per cent of their time actively exchanging information as they attend meetings, talk on the telephone, dictate letters and memos, receive and send e-mail, receive reports, read computer printouts, and so on (Hellriegel et al. 2001:230). Information can thus be described as the glue that holds the organisation together. In essence, the importance of information management is listed in table 1. 
Table 1: $\quad$ The importance of information management

- Business success depends on goal achievement

- Goal achievement depends on sound decisions

- Sound decisions depend on good information.

Source: Adapted from Lessing \& Scheepers 2001:5

Therefore, it can be deduced that managing information as a resource is an important managerial activity. Information management is described by Lessing \& Scheepers (2001:3) as " $\ldots$ the management of information as a resource of an enterprise by applying sound management principles, including planning, organising, development of and control over data and information, integrating people, hardware, software and systems, converting data into information, and utilising the information ethically in decision-making for goal achievement."

From the above definition of information management, it is obvious that data management is an important function of information management. Data management is defined by Rob \& Coronel (2000:5) as "... a discipline that focuses on the proper generation, storage, and retrieval of data". Thus it can be said that by accessing relevant data efficiently, sound management decisions can be made.

\section{INFORMATION AS A RESOURCE}

Is information a resource? Eaton \& Bawden (1991:156) suggest that information is a resource that should be managed like other resources (i.e. people, money, land and equipment). This implies applying resource management techniques, like planning, costing, budgeting and evaluating, to the information resources of the firm, and assigning the position for information resources management responsibilities to more senior levels within the organisation (Marchand \& Horton 1986:122).

Eaton \& Bawden (1991:164) show that information can only be managed as a resource if the following three conditions are fulfilled:

- The production of the information is undertaken to contribute to some purpose of the organisation.

- The relationship of the information to the achievement of the stated purpose can be clearly shown.

- The relationship can be empirically tested.

Eaton \& Bawden (1991:162) then go on to list several distinctions between information as a resource and traditional, tangible resources. This is shown in Table 2. 
Table 2: $\quad$ THE DISTINCTION BETWEEN INFORMATION AND TANGIBLE RESOURCES

\begin{tabular}{|ll|}
\hline $\begin{array}{l}\text { Characteristic } \\
\text { Value of information }\end{array}$ & $\begin{array}{l}\text { Description } \\
\text { The value of information, unlike that of tangible resources, is simply not readily } \\
\text { quantifiable. Its value depends upon its context and its use by particular users } \\
\text { on particular occasions. }\end{array}$ \\
$\begin{array}{l}\text { Consumption of } \\
\text { information }\end{array}$ & $\begin{array}{l}\text { The consumption consequences attached to finite resources are not applicable } \\
\text { to information. Information is not lost or diminished when it is given to others, } \\
\text { although its usefulness for particular purposes may be decreased. }\end{array}$ \\
$\begin{array}{l}\text { Dynamics of } \\
\text { information }\end{array}$ & $\begin{array}{l}\text { Information is a dynamic force for change to the system within which it } \\
\text { operates; a formative, organizing entity rather than an accumulated stockpile } \\
\text { of facts. } \\
\begin{array}{l}\text { Life-cycle of } \\
\text { information }\end{array}\end{array} \quad \begin{array}{l}\text { The life-cycle idea is an inappropriate over-simplification. Information can have } \\
\text { multiple life-cycles, as ideas come into, move out of, and finally come back into } \\
\text { fashion. }\end{array}$ \\
$\begin{array}{l}\text { Individuality of } \\
\text { information }\end{array}$ & $\begin{array}{l}\text { Information comes in many different forms, and is expressed in many different } \\
\text { ways. }\end{array}$
\end{tabular}

Source: Adapted from Eaton \& Bawden 1991:162

Table 2 is important when considering what data to manage as well as how to manage data. Because data management is an important function of information management, it is critical that data must be accurate and relevant so that it may be processed into information, which is regarded as a valuable resource.

Besides the importance of information as a resource, it is also appropriate to view information as a commodity. The Oxford English Dictionary (1992:166) describes a commodity as an "article of trade". From this definition, the question arises: is information traded?

The sheer mass of information that exists in organisations has raised new problems, such as which information to keep and the most cost effective means of managing that information. Another problem is that some information can no longer be purchased outright; it is held in databases and a charge is made for each access to the information (Crawford 1988:42). Therefore, it can be said that information can be managed as a commodity.

\section{THE NEW ECONOMY}

The so-called 'new economy', or information economy, is one where information-rich goods and services make up the greatest proportion of the GDP and/or where information workers 
constitute the majority of the workforce (Van Zanten 2000:Internet). Many of the world's developed countries have now entered this stage. The new economy is affected by the fast developing network technology (for example telecommunications, Internet and intranets). It refers to the new world of business that has evolved, and the new community that works in it: the people who are committed to new ways of working, competing, living and growing. Van Zanten (2000:Internet) believes that there are four major factors that have driven the change to the new economy. These include technology, the war of talent, globalisation and intangibles. Each of these factors is discussed below.

\section{- Technology}

In the last decade, communications have been revolutionised. The advent of digital technology, the rise of the cellular phone and the creation of the Internet have occurred. The effect of this is to make it easier for people to communicate with each other than ever before. The most exciting new technologies are focused on connecting people to each other via phones, computers and even televisions. These same technologies are also facilitating communications between businesses and between businesses and individuals. These interactions go beyond simply communicating, however - they are allowing a new type of business to be carried out, namely e-business.

\section{- The war of talent}

People, and more importantly their skills and ideas, are the prime resource of the new economy - a resource which is becoming increasingly scarce. Companies are suffering a shortage of skilled people.

\section{- Globalisation}

Globalisation has resulted in the world becoming smaller. Industries have been deregulated, monopolies broken and competition welcomed. Communications technologies from the telephone to the email have shrunk the world. The creation of trading agreements has brought barriers down and has led to even further economic and political integration.

\section{- Intangibles}

Companies have recognised that they can create and realise value through their intangible assets, such as their people, brands, customer and supplier relationships and intellectual property. Some companies now focus exclusively on these assets. These changes have resulted in a reassessment of business models. New business models have emerged and new intermediaries have been created.

These four factors and, subsequently, the new economy, are important because companies must be able to adapt quickly to changes in the environment in order to survive and, more importantly, to earn above-average returns. Proper data management leads to valuable 
information, which, according to Hitt et al. (2003:16), is a critical organisational resource and is increasingly a valuable source of competitive advantage.

\section{MANAGING DATA: THE TRADITIONAL FILE ENVIRONMENT}

The discussion in Rob \& Coronel (2000:8) of files and file systems as part of the historical roots of the database, provides insight as to how the data management process has evolved. They describe that, in the recent past, a manager of almost any small organisation was (and sometimes still is) able to keep track of necessary data by using a manual file system. Such a file system was traditionally composed of a collection of file folders, each properly tagged and kept in proper sequence in a filing cabinet.

As long as data collection was relatively small and an organisation's managers had few reporting requirements, the manual system served its role as a data repository. However, as organisations grew and as reporting requirements became more complex, keeping track of data in a manual file system became more difficult and time-consuming. Consequently, the pressure built up to design a computer-based system that would track data and produce required reports.

Laudon \& Laudon (2002:208) describe the historical development of computer-based file management. They state that most organisations began processing information on a small scale, automating one application at a time. Systems tended to grow independently and not according to some 'grand plan'. Each functional area tended to develop systems in isolation from other functional areas. Each application, of course, required its own files and its own computer program to operate. In companies as whole entities, this process led to multiple master files created, maintained, and operated by separate divisions or departments. As this process continued for five or ten years, organisations became saddled with hundreds of programs and applications, with no one who knew what they were doing, what data they used, and who was using the data.

Lessing \& Scheepers (2001: 69) list the following factors as typical problems that can occur with the traditional file environment:

- Data redundancy - the presence of duplicate data in multiple data files.

- Lack of data sharing and availability - information in different files and in different parts of the organisation cannot be related, since special computer programs have to be written to retrieve data from each independent file. In addition to this, the "owners" of the data were reluctant to make "their" data available to other users.

- Lack of flexibility - information requested by anticipated requests takes too long to retrieve

- Program-data dependence - any change in data requires a change in all programs that access the data.

- Diffused data ownership - more than one data file has the same information in different formats. In addition to this, it was not always clear who was the "owner" of the data and thus who carried the responsibilities for its integrity and maintenance. 
- Data confusion - data is collected and maintained in so many different places, and therefore the same data item may have different meanings in different parts of the organisation.

- Poor security - because of redundant data, and multiple owners of data with varying degrees of concern about the importance of certain data elements, and hence varying degrees of concern about its security, it is impossible to know whether each piece of the same information had been made secure.

From the above discussion it is obvious that the need for a more structured and practically efficient approach to managing data became apparent. The solution to this need is the database approach to data management, which is discussed in the following section.

\section{THE IMPORTANCE OF DATABASE MANAGEMENT SYSTEMS}

Before the importance of database management systems (DBMS) can be understood, it is necessary to define the terms database and system .

- A database can be described as "an integrated collection of data" (Deitel et al. 1999:768). It can also be stated as "an organised body of related information". This collection of data is organised to serve many applications efficiently by centralising the data and minimising redundant data (Laudon \& Laudon 2002:209).

- A system is "a group of independent but interacting (interrelated) components comprising a unified whole and working together towards a common goal by accepting inputs, and in a structured conversion process, producing required outputs" (Lessing \& Scheepers 2001:37).

From the two above definitions, it is clear that a database system is the collection of data whereby the data is organised through a structured conversion process in order to produce required outputs. Deitel et al. (1999:768) describe what components a database system consists of, by defining a database system as the data itself, the hardware on which the data resides, the software (or DBMS) that controls the storage and retrieval of data, and the users themselves. Deitel et al. (1999:768) further list the following advantages of database systems:

- Redundancy can be reduced

- Inconsistency can be avoided

- The data can be shared

- Standards can be enforced

- Security restrictions can be applied

- Integrity can be maintained

- Conflicting requirements can be balanced. 
In a sense, a database resembles a very well organised electronic filing cabinet in which powerful software, known as a DBMS, helps manage the cabinet's contents (Rob \& Coronel 2000:5). The DBMS acts as an interface between application programs and the physical data files. The DBMS relieves the programmer or end-user from the task of understanding where and how the data are actually stored (Laudon \& Laudon 2002:209).

Because data are the crucial raw material from which information is derived, there are many good reasons why DBMS's are important in the information-based society. Rob \& Coronel (2000:5) list some of these reasons as illustrated in table 3.

\section{Table 3: $\quad$ THE IMPORTANCE OF DATABASE MANAGEMENT SYSTEMS}

- $\quad$ Since data are so important, we must have a good way of managing such data. The DBMS helps make data management much more efficient and effective than it was before the DBMS became a reality.

- The DBMS contains a query language that makes it possible to produce quick answers to ad hoc queries.

- Wider access to well-managed data promotes an integrated view of the organisation's operations.

Source: Adapted from Rob \& Coronel 2000:5

Thus it can be seen that database management systems are imperative for effectively managing data as a resource.

\section{DATA MANAGEMENT TRENDS AND DEVELOPMENTS}

Because of the dynamic nature of organisations and, subsequently, their information, data management is constantly changing and it is vital that managers remain up to date with the latest trends that are prevalent in the field of data management. Some of these broader trends include outsourcing, data reuse, data re-engineering, archiving, data warehousing and data mining. These trends are briefly introduced below.

\section{- Outsourcing}

The current most important trend in not only data management, but also information technology management, is outsourcing. Outsourcing is the purchase of a value-creating activity from an external supplier (Hitt et al. 2003:95). In terms of information management, outsourcing would thus be the hiring or purchasing of the products or services of one or more external companies to conduct or supply an information management-related activity, such as web design, software engineering, database design, or network installations. Cost-cutting measures are the first and foremost driver for existing and potential outsourcing customers. Software providers are aggressively looking for ways to take costs out of delivery of service to their customers.

Moving some services to offshore or near shore locations is another cost-cutting technique. For example, many companies make use of the services of Web hosting companies that are 
not based in the domestic country to store and manage their Websites. By doing so, these companies profit from the wage and overhead cost differential between countries, utilising the location-free advantages of technology and global connectivity. In essence, business transformation outsourcing is driving software providers to develop or enhance vertical solutions and is also driving buyers to seek benchmarking services to analyse the value components achieved through outsourcing (Goolsby 2003:Internet).

\section{- Data reuse}

Data reuse relates to the repeated utilisation of the same data for the same or similar tasks, or it can relate to the further use or extension of data for a different purpose (Hicks 2002:273). Furthermore, the reuse of data is predominantly for the evaluation of measurable quantities, qualities or performance, as well as the evaluation of decision processes. The reuse of data and information typically aims to make available the experiences of individual knowledge or organisational knowledge in order to better inform and enable future design activities. Examples of reuse include the selection of decision alternatives, the utilisation of new technologies, or choosing suppliers.

\section{- Data re-engineering}

What happens when systems start getting old or outdated? Legacy systems are old software systems that are essential for business process support. Companies rely on these old systems so they must keep them in operation. Software re-engineering is concerned with reimplementing legacy systems to make them more maintainable (Sommerville 2001:623).

The storage, organisation and format of the data processed by legacy programs may have to evolve to reflect changes to the software. The process of analysing and reorganising the data structures and, sometimes, the data values in a system to make it more understandable is called data re-engineering (Sommerville 2001:634). Data re-engineering is only necessary if the functionality of a system is changed.

\section{- Archiving}

Companies today store more information than ever before and explosive database growth continues at an unprecedented rate. As a result, two challenges are posed to companies:

- users are demanding access to information whenever they need it, and

- slow response times are totally unacceptable.

Companies can now solve the problems of massive exponential data growth and the need for proper data management through a technology called active archiving (Norris 2002:33).

These solutions rely on a complete understanding of relational databases and the relationships between records and tables, which enables them to safely archive and remove precise subsets of rarely used data from complex relational databases with 100 percent accuracy. In addition, not only can the information be removed simply and safely, all records 
can be stored as much as necessary without losing any of the referential integrity. This means that if one data aspect is changed in one database, the change will be reflected in all related databases.

\section{- Data warehouses and data mining}

A data warehouse is an integrated, subject-orientated, time-variant, non-volatile database that provides support for decision-making (Rob \& Coronel 2000:579). It can also be described as a database that stores current and historical data of potential interest to managers throughout the company (Laudon \& Laudon 2002:221).

The data from internal sources are ideally combined with data from external sources and reorganised into a central database designed for management reporting and analysis.

Data mining is used to perform data analysis in order to discover previously unknown data characteristics, relationships, dependencies or trends. These findings are then used to predict business behaviour. Data mining tools initiate analyses to create knowledge (Rob \& Coronel 2000:609). This effectively means that data mining is extremely powerful for decision-making purposes, and is an excellent aid to support strategy making.

\section{CLOSURE}

Organisations need to manage their data assets very carefully to make sure that they can be easily accessed and used by managers and employees across all organisational levels.

Implementing a DBMS challenges the allocation of power at senior levels, the ownership and sharing of information, and the patterns of organisational agreement. Management need to make sure that employees at all levels understand the benefits of managing data electronically, and more importantly, all employees and managers must know how to make the most of the data provided and therefore require the skills of how to use databases. If employees do not have these skills, then organisations will not reap the benefits even if a substantial amount of money has been spent on hardware and software for a database environment.

The full benefits of a DBMS are often intangible and medium to long-term. Organisations will need to continuously evaluate the costs and benefits of implementing a database environment with the DBMS capabilities.

Lastly, but most importantly, an organisation's data model should reflect its key business processes and decision-making requirements. That is the sole purpose of data management - to aid in faster and more effective and improved decision-making to achieve goals and objectives and ultimately business success. 


\section{BIBLIOGRAPHY}

CRAWFORD M. 1988. Information as a commodity. Aslib Information, 17(2):42-43.

DEITEL HM, DEITEL PJ \& NIETO TR. 1999. Visual Basic: how to program. New Jersey : Prentice Hall.

EATON JJ \& BAWDEN D. 1991. What kind of resource is information? International Journal of Information Management, 11(2):157-165.

GOOLSBY K. 2003. What you need to know about IT outsource trends for 2003. [nternet: http://www. outsourcing- information-technology.com/ trends2003.html.

HELLRIEGEL D, JACKSON SE \& SLOCUM J. 2001. Management. Cape Town : Oxford.

HITT MA, IRELAND RD \& HOSKISSON RE. 2003. Strategic Management: competitiveness and globalization. $5^{\text {th }}$ ed. Ohio : Thomson.

HICKS F. 2002. A framework for the requirements of capturing, storing and re-using information and knowledge in engineering design. International Journal of Information Management, 22(2002):263-280.

LAUDON KC \& LAUDON JP. 2002. Management Information Systems: managing the digital firm. $7^{\text {th }}$ ed. New Jersey : Prentice Hall.

LESSING N \& SCHEEPERS C. 2001. Information is a management issue. $5^{\text {th }}$ ed. Johannesburg : CSIC.

MARCHAND DA \& HORTON FW. 1986. Infotrends: profiting from your information resources. Wiley.

NORRIS D. 2002. Exploding databases? Managing Information, 9(6):32-33.

THOMPSON DJ. 1992. The Pocket Oxford Dictionary. $8^{\text {th }}$ ed. New York : Oxford University Press.

ROB P \& CORONEL CM. 2000. Database Systems: design, implementation, and management. $4^{\text {th }}$ ed. Cambridge : Course.

SOMMERVILLE I. 2001. Software Engineering. $6^{\text {th }}$ ed. Essex : Pearson.

VAN ZANTEN T. 2000. Techniques used by Arthur Andersen to add value to information. South African Journal of Information Management, 2(2/3). [Internet: www:http://general.rau.ac.za/Infosci/RAUjournal/n default.asp. 